\title{
Experimental analyses of dynamical systems involving shape memory alloys
}

\author{
Enemark, Søren; Savi, Marcelo A.; Santos, IImar F.
}

\section{Published in:}

Smart Structures and Systems

Link to article, DOI:

10.12989/sss.2015.15.6.1521

Publication date:

2015

Document Version

Publisher's PDF, also known as Version of record

Link back to DTU Orbit

Citation (APA):

Enemark, S., Savi, M. A., \& Santos, I. F. (2015). Experimental analyses of dynamical systems involving shape memory alloys. Smart Structures and Systems, 15(6), 1521-1542. https://doi.org/10.12989/sss.2015.15.6.1521

\section{General rights}

Copyright and moral rights for the publications made accessible in the public portal are retained by the authors and/or other copyright owners and it is a condition of accessing publications that users recognise and abide by the legal requirements associated with these rights.

- Users may download and print one copy of any publication from the public portal for the purpose of private study or research.

- You may not further distribute the material or use it for any profit-making activity or commercial gain

- You may freely distribute the URL identifying the publication in the public portal 


\title{
Experimental investigation of vibration reduction using shape memory alloys
}

Journal of Intelligent Material Systems and Structures $0(0) 1-15$

(C) The Author(s) 2012

Reprints and permissions:

sagepub.co.uk/journalsPermissions.nav DOI: I0.1I77/I045389X1246/696 jim.sagepub.com (S)AGE

\author{
Ricardo AA Aguiar', Marcelo A Savi ${ }^{2}$ and Pedro MCL Pacheco'
}

\begin{abstract}
Smart materials have a growing technological importance due to their unique thermomechanical characteristics. Shape memory alloys belong to this class of materials being easy to manufacture, relatively lightweight, and able to produce high forces or displacements with low power consumption. These aspects could be exploited in different applications including vibration control. Nevertheless, literature presents only a few references concerning the experimental analysis of shape memory alloy dynamical systems. This contribution deals with the experimental analysis of shape memory alloy dynamical systems by considering an experimental apparatus consisted of low-friction cars free to move in a rail. A shaker that provides harmonic forcing excites the system. The vibration analysis reveals that shape memory alloy elements introduce complex behaviors to the system and that different thermomechanical loadings are of concern showing the main aspects of the shape memory alloy dynamical response. Special attention is dedicated to the analysis of vibration reduction that can be achieved by considering different approaches exploiting either temperature variations promoted by electric current changes or vibration absorber techniques. The results establish that adaptability due to temperature variations is defined by a competition between stiffness and hysteretic behavior changes.
\end{abstract}

\section{Keywords}

Shape memory alloys, smart materials, vibration reduction, control, adaptive absorber

\section{Introduction}

The remarkable properties of shape memory alloys (SMAs) are attracting much technological interest, motivating different applications in several fields of science and engineering. Aerospace, biomedical, and robotics are some areas where SMAs have been applied (Denoyer et al., 2000; Lagoudas, 2008; Machado and Savi, 2002, 2003; Paiva and Savi, 2006; Van Humbeeck, 1999; Webb et al., 2000).

Dynamical systems are included among several applications that incorporate SMA elements to the system to exploit their thermomechanical behavior. One possibility is to exploit the high dissipation capacity related to the hysteretic behavior. Another interesting application is related to the temperature-induced phase transformation that can be used to promote stiffness variations and, as a consequence, alters system dynamical characteristics. Both alternatives indicate SMA elements to be employed to promote vibration reduction in dynamical systems. Several research efforts presented different aspects of SMA applications in dynamical systems that include vibration absorbers and composite structures (Birman, 2008; Elahinia et al., 2005; Nae et al., 2004; Rustighi et al., 2003, 2005a, 2005b; Savi et al., 2011; Tiseo et al., 2010; Williams et al., 2001, 2002, 2005).
In general, dynamical behavior of SMA systems is related to complex behaviors, presenting periodic, quasi-periodic, and chaotic responses (for details, see Bernardini and Rega, 2005, 2011a, 2011b; Machado et al., 2003, 2009; Savi et al., 2002, 2008, 2011; Savi and Pacheco, 2002). Recently, SMAs are being used in impact systems where the dissipative characteristics of SMA can produce very different behaviors when compared with elastic systems (Santos and Savi, 2009; Sitnikova et al., 2010).

This article deals with the experimental analysis of the dynamical behavior of systems with SMA elements. An experimental rig was designed and built to observe the details of the dynamical behavior. This apparatus is composed of low-friction cars free to move in a rail and connected to an SMA helical spring. Several

\footnotetext{
'Department of Mechanical Engineering, CEFET/RJ, RJ, Brazil

${ }^{2}$ Department of Mechanical Engineering, COPPE, Universidade Federal do Rio de Janeiro, RJ, Brazil

Corresponding author:

Marcelo A Savi, Department of Mechanical Engineering, COPPE, Universidade Federal do Rio de Janeiro, PO Box 68.503, 21.941.972, RJ, Brazil.

Email: savi@ufrj.br
} 
sensors are employed in order to monitor all important phenomena involved. Tests are performed in order to observe the influence of different system aspects, such as the temperature dependence and the hysteretic behavior. System changes are employed using logical arguments allowing us to conclude the main aspects of SMA system dynamics. Basically, two different systems are investigated: one and two degrees of freedom. A shaker that provides harmonic forcing excites the system. The vibration analysis reveals that SMA elements are responsible for the complex behavior of the system. Different thermomechanical loadings are of concern showing the main aspects of the SMA dynamical response. Special attention is dedicated to vibration reduction that can be achieved by considering different approaches exploiting either temperature variations promoted by electric current changes or vibration absorber techniques. Adaptability of SMA vibration absorber is discussed showing situations where it is possible to alter the tuned vibration frequency by changing the temperature.

The main goal of this contribution is to define important aspects of SMA dynamical behavior, focusing special attention on vibration reductions. Under this assumption, it is important to observe that temperature variations can induce both stiffness and hysteretic changes. Although these aspects are well-known behaviors of SMA systems, it is not clear how they interact to produce the dynamical response of the SMA systems. In this regard, it is important to highlight that several references are discussing the applicability of SMAs in dynamical systems considering models that are just able to represent the stiffness changes induced by temperature variations. This contribution presents experimental results that show that both effects play a competition in order to define the system dynamical response. The authors are not aware with the experimental works that reach similar conclusions, and hence, they agree that this investigation brings new aspects that need to be considered in a proper design of SMA dynamical systems.

\section{Experimental apparatus}

The dynamical behavior of SMA oscillators is studied with the use of an apparatus built and designed especially to monitor the main phenomena involved in an SMA system. It is composed of low-friction cars free to move in a rail and two different configurations are of concern: one and two degrees of freedom.

The one-degree-of-freedom (1DoF) system is composed of a car connected to two springs: elastic and SMA spring. The elastic spring is connected to an excitation system composed of an electrodynamic shaker (LabWorks ET-126 with $58 \mathrm{~N}$ peak force capacity) connected to the system with the aid of an extra car. The

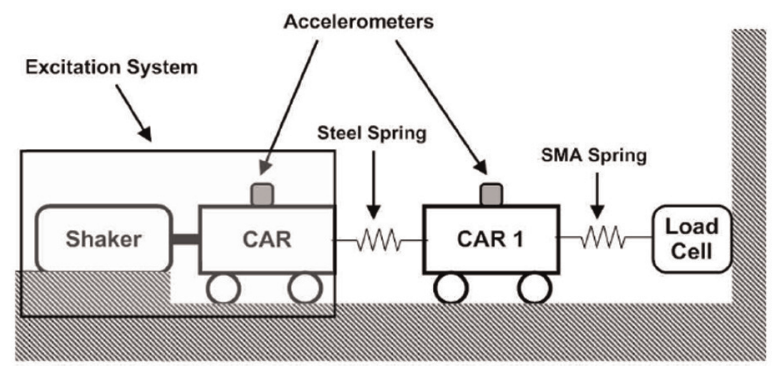

(a)

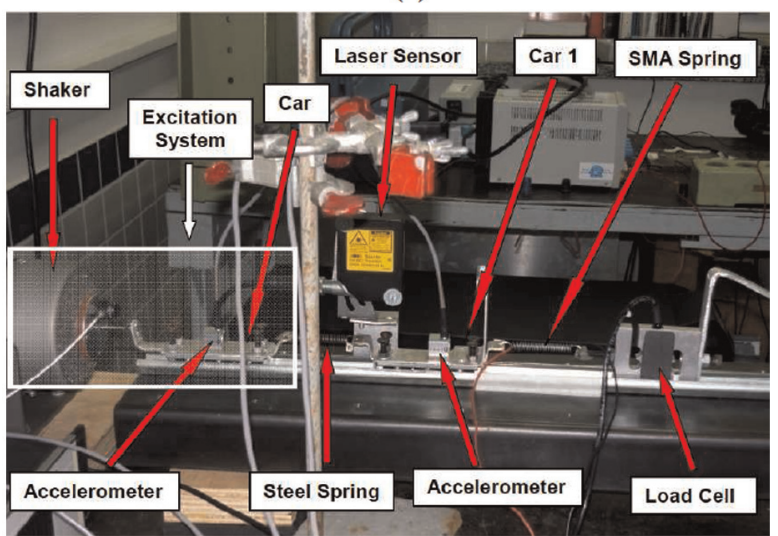

(b)

Figure I. Experimental apparatus to study the dynamical behavior of one-degree-of-freedom SMA oscillator: (a) schematic diagram and (b) picture of the system. SMA: shape memory alloy.

SMA spring is fixed to the load cell (Alfa SV-20 with 196-N capacity). Figure 1 presents the schematic diagram together with a picture of the $1 \mathrm{DoF}$ system.

The two-degree-of-freedom (2DoF) system considers a new car connected to the system. This system is employed to represent a vibration absorber consisted of a primary system (car 1) with linear elastic characteristics and a secondary system (car 2) consisted of a linear elastic spring together with an SMA spring. Therefore, this system is composed of two elastic springs. On one side, there is a spring connected to the excitation system, and on the other side, there is a spring connected to the car of the secondary system. This new car is connected to an SMA spring that is connected to a load cell. Figure 2 presents the schematic diagram together with a picture of the $2 \mathrm{DoF}$ system.

The excitation system is mounted in a closed-loop configuration controlled by a vibration controller system (LabWorks VibeLab VL-145s Digital Sine Controller) with sine-sweep controller capability. All cars are monitored by accelerometers and transducers (Kyowa AS-10GB with $10 \mathrm{~g}$ capacity) connected to a data acquisition system (HBM Spider 8) with an acquisition rate of $400 \mathrm{~Hz}$. A laser sensor is also employed to monitor displacements (Micro-Epsilon ILD 2220-100). Temperature variations are induced through Joule effect by the application of electric current using a 


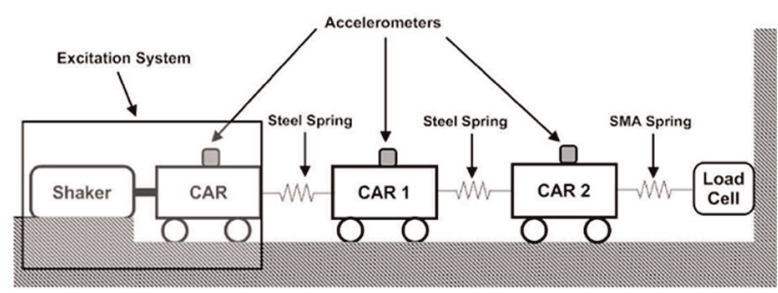

(a)

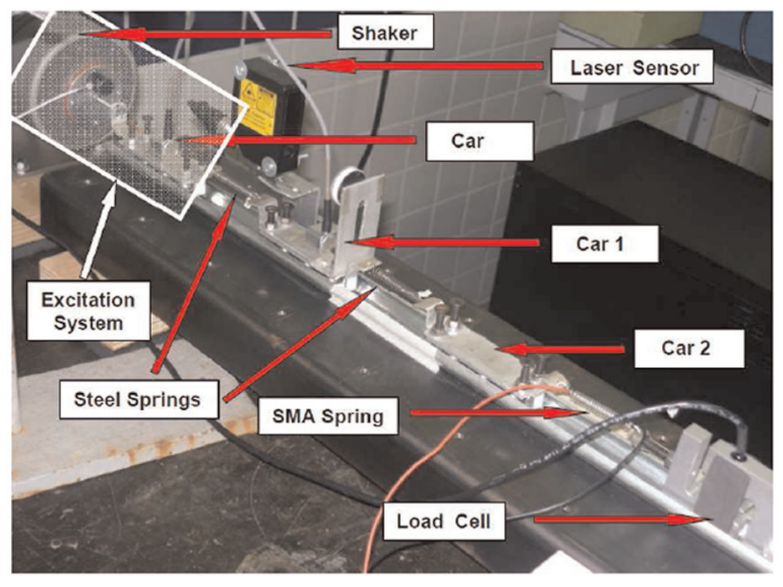

(b)

Figure 2. Experimental apparatus to study the dynamical behavior of two-degree-of-freedom SMA oscillator: (a) schematic diagram and (b) picture of the system. SMA: shape memory alloy.

Table I. Laser transducer and accelerometers technical specifications.

\begin{tabular}{lll}
\hline & $\begin{array}{l}\text { Laser } \\
\text { transducer }\end{array}$ & Accelerometers \\
\hline Resolution & $1.5 \mu \mathrm{m}$ & - \\
Linearity error & $\leqslant 0.03 \% \mathrm{FSO}$ & $\pm \mathrm{I} .0 \% \mathrm{RO}$ \\
Response time/release time & $<0.15 \mathrm{~ms}$ & - \\
Maximum switching frequency & $20 \mathrm{kHz}$ & $350 \mathrm{~Hz}$ \\
Hysteresis & - & $\pm 1.0 \% \mathrm{RO}$ \\
\hline
\end{tabular}

FSO: Full scale output

RO: Rated output

stabilized current source (Minipa MPL-1303). An infrared camera FLIR A-320 monitors the temperature. Table 1 presents the technical specifications of laser transducer and accelerometers.

\section{Spring characterization}

This section discusses the characterization of the elastic and SMA springs employed in the experimental rig. The characterization of the SMA spring is of special importance in order to define proper range of applicability in the experimental rig. The general thermomechanical analysis of SMA springs is presented in Aguiar et al. (2010) where modeling and simulations are treated. Here, the characterization is performed from
Table 2. Stiffness of the springs.

\begin{tabular}{lll}
\hline Spring & Type & $k(\mathrm{~N} / \mathrm{mm})$ \\
\hline I (steel) & Linear elastic & 0.348 \\
2 (steel) & Linear elastic & 0.573 \\
3 (steel) & Linear elastic & 0.528 \\
SMA & Nonlinear & Nonlinear \\
\hline
\end{tabular}

SMA: shape memory alloy.

force-displacement, displacement-current, and differential scanning calorimetry (DSC) tests, defining important aspects related to the SMA phase transformations.

Elastic tension helical springs are made of steel with an external diameter of $7.3 \mathrm{~mm}$ and a wire diameter of $0.85 \mathrm{~mm}$. Moreover, the system uses an SMA helical spring built with NiTi that presents martensitic phase at room temperature. This SMA spring has an external diameter of $6 \mathrm{~mm}$, a wire diameter of $0.75 \mathrm{~mm}, 20$ active coils, and an activation temperature in the range of $45^{\circ} \mathrm{C}-55^{\circ} \mathrm{C}$. Table 2 shows the stiffness, $k$, of the elastic springs used in experiments measured from force-displacement tests.

The tensile test device shown in Figure 3 is employed in force-displacement and displacement-current tests. Basically, this device is composed of a rigid frame that has a load cell (Alfa SV-20 with $196 \mathrm{~N}$ capacity) fixed at the top. SMA spring is connected to the load cell, and the other end is attached to the rod of a resistive displacement transducer (Gefran PY-1-F-100 with 100 $\mathrm{mm}$ span). Both transducers are connected to a data acquisition system (HBM Spider 8). A fluid reservoir is attached to the other end of the transducer rod in order to produce mechanical loadings. The SMA spring is subjected to mechanical loading controlled by the fluid level of the reservoir, which is performed by changing the vertical position of a second fluid reservoir that is connected to the first one by a tube. This procedure allows one to apply smooth loading-unloading conditions to the spring element. Temperature variations are induced through Joule effect by the application of an electric current using a stabilized current source (Minipa MPL-1303). The SMA spring is subjected to different thermomechanical loading-unloading processes in order to reproduce shape memory and pseudoelastic effects.

Initially, SMA spring is characterized by considering electric current changes with a constant stress level. This test has the objective to establish a relation between electric current and phase transformation. Figure 4 presents the displacement-electric current curve showing the hysteresis loop that allows one to identify the electric current value related to phase transformation temperatures. Besides this test, the DSC analysis is developed using Netzsch DSC-200 F3 calorimeter. Based on this analysis, phase transformation 


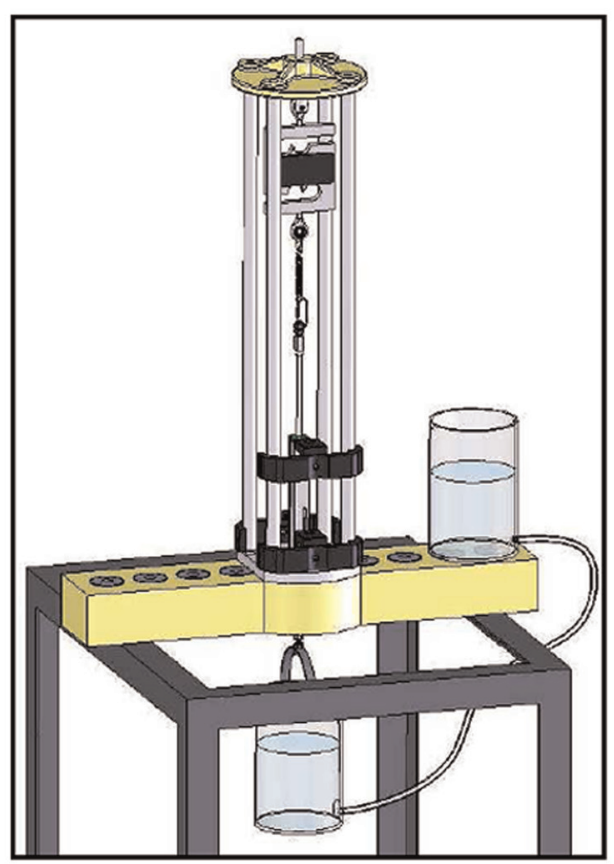

(a)

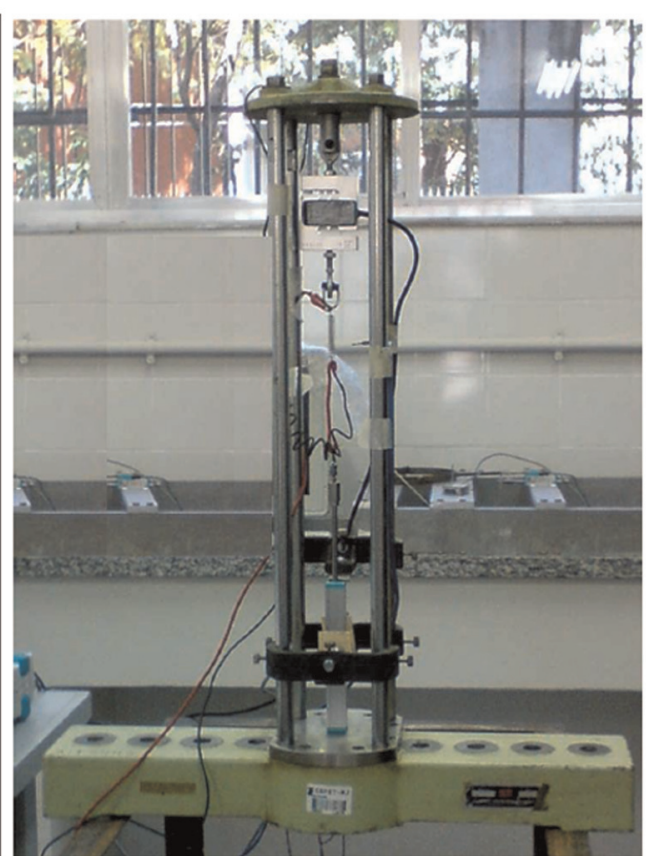

(b)

Figure 3. Tensile test device for thermomechanical characterization of SMA helical springs: (a) schematic diagram and (b) picture. SMA: shape memory alloy.

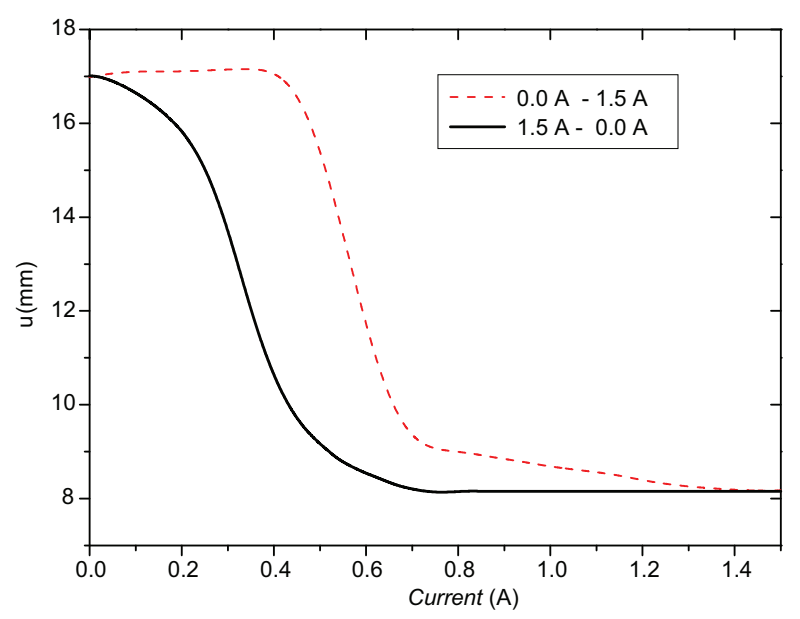

(a)

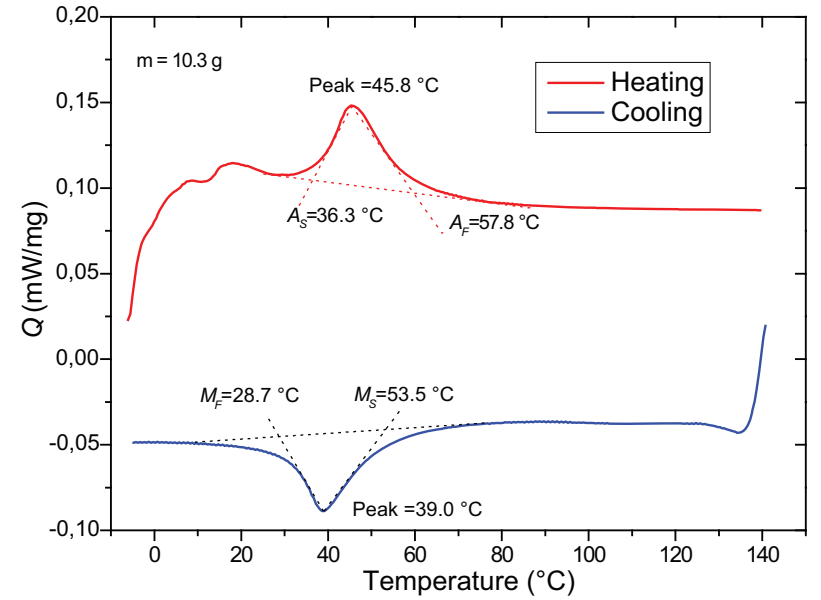

(b)

Figure 4. Experimental data: (a) displacement-electric current curves and (b) DSC analysis. (color in electronic version) DSC: differential scanning calorimetry.

temperatures are defined: $A_{s}=36.3^{\circ} \mathrm{C}, A_{f}=57.8^{\circ} \mathrm{C}$, $M_{s}=53.5^{\circ} \mathrm{C}$, and $M_{f}=28.7^{\circ} \mathrm{C}$.

SMA spring force-displacement curves are now in focus trying to represent shape memory effect (SME) and pseudoelasticity. The SME is imposed by considering a two-stage thermomechanical test: (a) a mechanical loading-unloading followed by (b) a thermal heating-cooling. The first stage promotes a residual strain that is eliminated during the second stage.
Three different maximum load levels are considered: $3,3.5$, and $4 \mathrm{~N}$. The heating of the SMA helical spring to a high temperature where martensite is stable is performed by applying an electric current of $1.2 \mathrm{~A}$. The pseudoelastic test is performed by assuming a constant temperature loading together with a mechanical loading-unloading test. Two different mechanical loading-unloading procedures are performed being related to maximum load levels ( 7 and $8 \mathrm{~N}$ ) together 


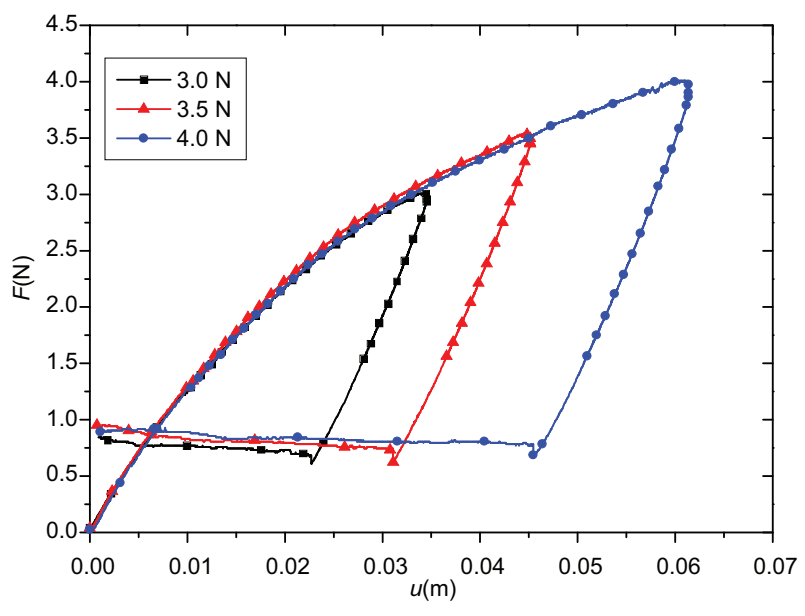

(a)

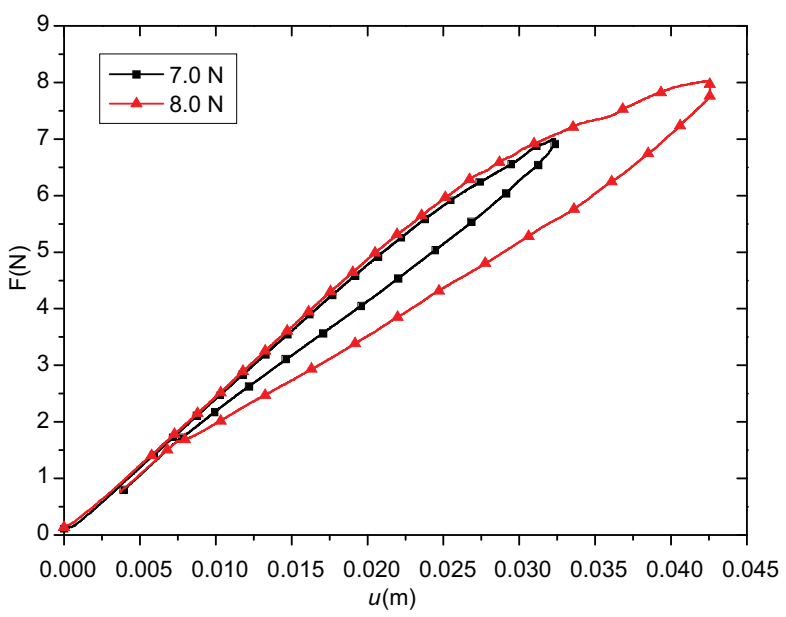

(b)

Figure 5. Experimental data related to the spring force-displacement: (a) shape memory effect and (b) pseudoelasticity. (color in electronic version)

with a constant temperature induced by applying an electric current of $0.8 \mathrm{~A}$.

Figure 5 presents experimental curves for both shape memory and pseudoelastic effects. At the beginning of each test, the SMA helical spring is at room temperature $\left(22^{\circ} \mathrm{C}\right)$, a situation where martensitic phase is stable. In order to assure that each test is done with a spring where its wire section has a homogeneous twinned martensitic phase distribution, the following process is applied. Initially, all mechanical loads are removed and then an electric current of $1.2 \mathrm{~A}$ is applied to the spring. Finally, the spring is subjected to cooling prescribed in order to allow a thermal equilibrium with the medium. The SME test is performed after this initial stage by imposing a mechanical loading that promotes the formation of detwinned martensite. This phase remains present after the mechanical loading removal, causing a residual displacement. At this point, an electric current of $1.2 \mathrm{~A}$ is applied and the SMA helical spring recovers part of the residual displacement developed during the loading stage. A residual load with a magnitude of approximately $1 \mathrm{~N}$ is still present at the end of the unloading as a consequence of the devices attached to the spring (e.g. resistive displacement transducer and fluid reservoir). A loading rate of approximately $2.7 \times 10^{-2} \mathrm{~N} / \mathrm{s}$ is used in the developed tests. Pseudoelastic test is performed by considering an applied electric current of $0.8 \mathrm{~A}$ that increases the SMA temperature promoting a phase transformation from twinned martensite to austenite. Afterward, mechanical loading-unloading process is imposed to the spring by considering two different maximum values: 7 and $8 \mathrm{~N}$. As expected, pseudoelastic test shows a complete reverse phase transformation after the loading is removed and, as a consequence, there is no residual displacement.

\section{DoF system}

The dynamical analysis of SMA system is first analyzed by considering a $1 \mathrm{DoF}$ oscillator. This system allows one to have a general comprehension about SMA system dynamics. Initially, free vibration is treated showing the temperature dependence of equilibrium points and responses. Afterward, forced vibration is considered highlighting the possibility of vibration reduction.

\section{Free vibrations}

Free vibration of a $1 \mathrm{DoF}$ system is now in focus by assuming that all external forces vanish. Experimentally speaking, a rigid support is used, instead of the shaker, to connect a spring that is connected to the oscillator mass. Laser sensor monitors the system movement. Figure 6 shows a schematic diagram of the device employed for free vibration tests together with a picture.

At the beginning of each test, a standard procedure is considered. The SMA helical spring in load-free condition is heated, by applying an electric current of 1.8 A during $60 \mathrm{~s}$. Afterward, SMA helical spring is cooled, and therefore it is expected that the spring presents martensitic phase. All of this process is performed without the action of any force and then the SMA spring is subjected to a preload of $2.6 \mathrm{~N}$.

After this procedure, free vibrations are evaluated by considering perturbations to the system. Essentially, the perturbation induces a change in displacement that represents initial conditions to the car at two different temperatures (obtained by applying an electric current on the SMA helical spring). After this, the car is free to move. Figure 7(a) presents the general analysis of free vibrations showing the application of different initial conditions for two different temperatures and the 


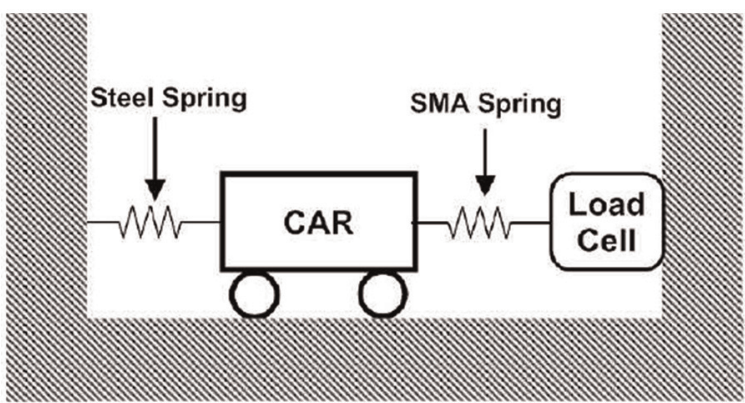

(a)

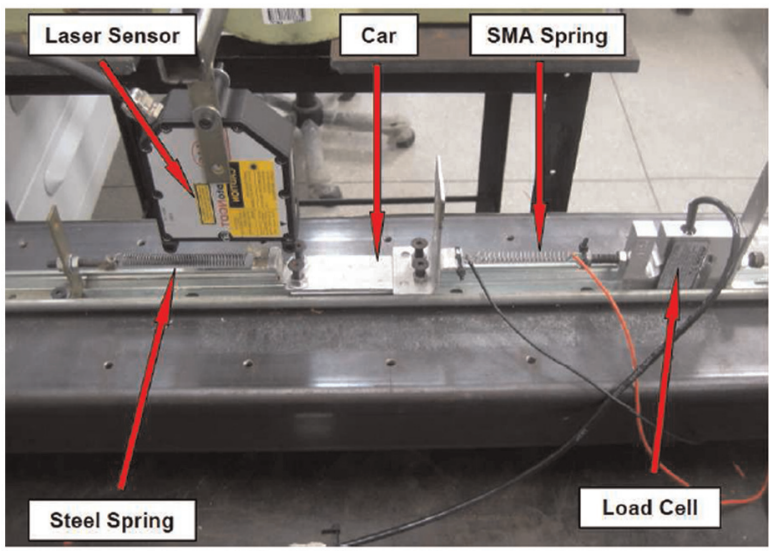

(b)

Figure 6. Experimental apparatus for free vibration analysis: (a) schematic diagram and (b) picture of the system. SMA: shape memory alloy.

consequent system response, highlighting some details of the movement.

Initially, the system is at rest when a perturbation of $1 \mathrm{~mm}$ is imposed to the car. This perturbation generates oscillations around the same equilibrium point that decreases until the system returns to the rest. It should be highlighted that the attenuation is caused by the system dissipation mainly due to the hysteretic behavior of the SMA spring. A greater perturbation is then imposed to the system $(7.3 \mathrm{~mm})$ and as a consequence, the system oscillates around a new position $(1 \mathrm{~mm})$. Note that the system presents the same qualitative behavior but oscillates around a different position. Figure 7(b) highlights the details of these two responses.

A temperature increase is now imposed to the system by applying an electric current of $1.8 \mathrm{~A}$ to the SMA spring. This temperature increase changes the equilibrium position again inducing the martensiteaustenite phase transformation. Under this condition, new perturbations are imposed to the system. Initially, a $3.2 \mathrm{~mm}$ displacement is imposed that is followed by oscillations around this position. Afterward, a $9.5 \mathrm{~mm}$ perturbation is imposed and the system presents the same qualitative behavior, oscillating around the same position. Figure 7(c) shows the details of the system response under the 1.8-A condition.
Finally, the current of $1.8 \mathrm{~A}$ is turned off representing a temperature decrease. Under this condition, austenite-martensite phase transformation is induced, and the system returns to the equilibrium point of the beginning of the test (Figure 7(a)).

\section{Forced vibrations}

Forced vibration tests are now conducted to evaluate the $1 \mathrm{DoF}$ response. Special attention is dedicated to consider the possibility of vibration attenuation using the temperature variation of the SMA. Temperature variation promotes phase transformation that changes the system characteristics as the equilibrium points and the SMA helical spring stiffness. Several situations involving the influence of temperature on the system dynamics are explored.

At the beginning of each test, a standard procedure is considered. The SMA helical spring in load-free condition is heated, by applying an electric current of 0.8 A in order to recover its original length. Afterward, SMA helical spring is attached to the device in a hightemperature condition, the SMA spring is subjected to an approximately preload of $6 \mathrm{~N}$, and the shaker provides an excitation with the amplitude of $0.25 \mathrm{~g}$. Before the signal acquisition, a stabilization period of $60 \mathrm{~s}$ is adopted. The system is subjected to sinusoidal excitation with a constant frequency. SMA helical spring temperature variation is obtained by changing the applied electric current.

Figure 8 shows experimental results involving SMA $1 \mathrm{DoF}$ oscillator. Basically, the system is subjected to a sinusoidal excitation with $8.22 \mathrm{~Hz}$ that coincides with the resonant frequency for $0.8 \mathrm{~A}$. The test starts with an electric current of $0.8 \mathrm{~A}$, and after $10 \mathrm{~s}$, this value is increased and stabilized on four new electric current values: 1.5, 2, 2.5, and $3 \mathrm{~A}$. Two different signals are presented: acceleration measured by accelerometer (left panel) and displacement measured by the laser sensor (right panel). The accelerometer picture also presents the excitation signal. Note that vibration reduction is achieved by the variation of SMA temperature.

An infrared camera monitors the temperature variation imposed by the electric current. Figure 9 shows an infrared thermal image of the SMA spring during the experimental procedure where temperature variation promotes vibration reduction. Figure 9(a) is related to a current of 0.8 A, while Figure 9(b) is associated with a current of $3.0 \mathrm{~A}$.

At this moment, we consider the analysis of a specific temperature variation associated with an electric current increase from 0.8 to 2.0 A. Figure 10(a) presents the accelerometer signal showing the details of the reduction that is basically related to two essential issues: stiffness change and hysteresis. Mainly, the stiffness change is related to temperature-induced phase transformation, from austenite to martensite and vice 

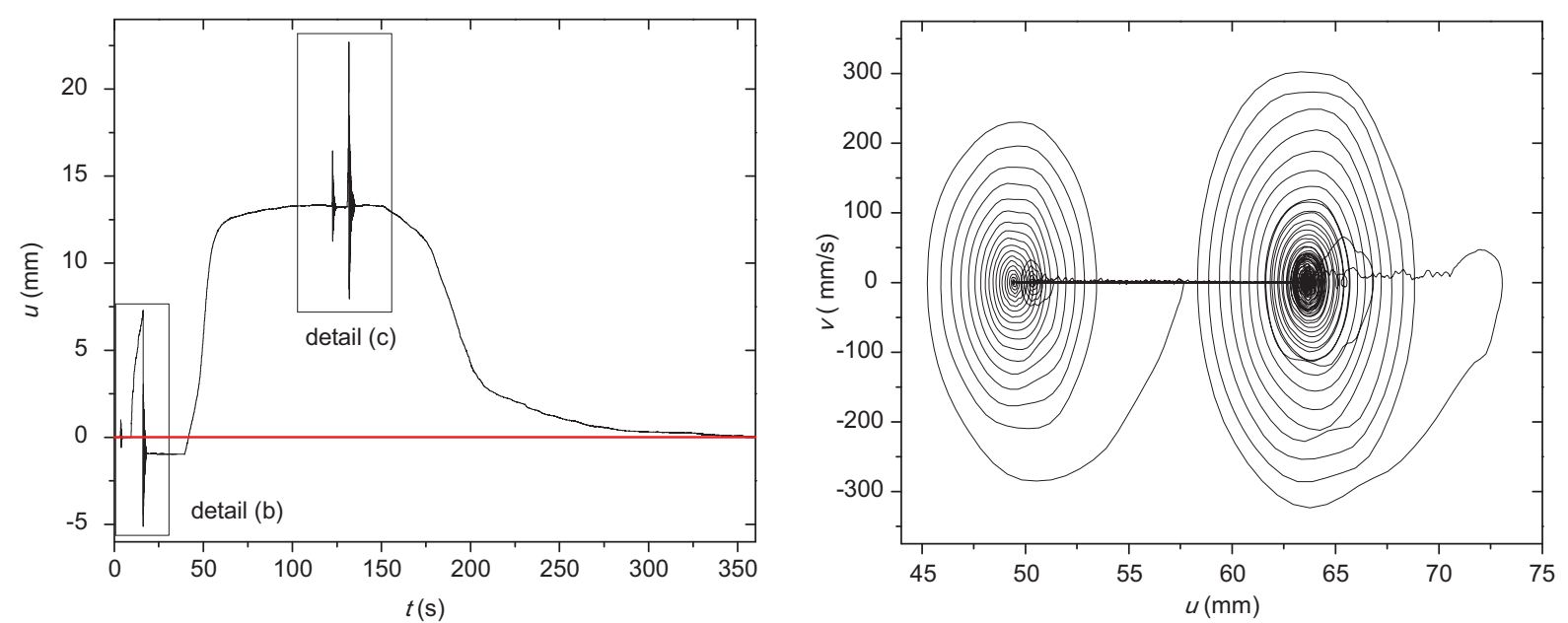

(a)
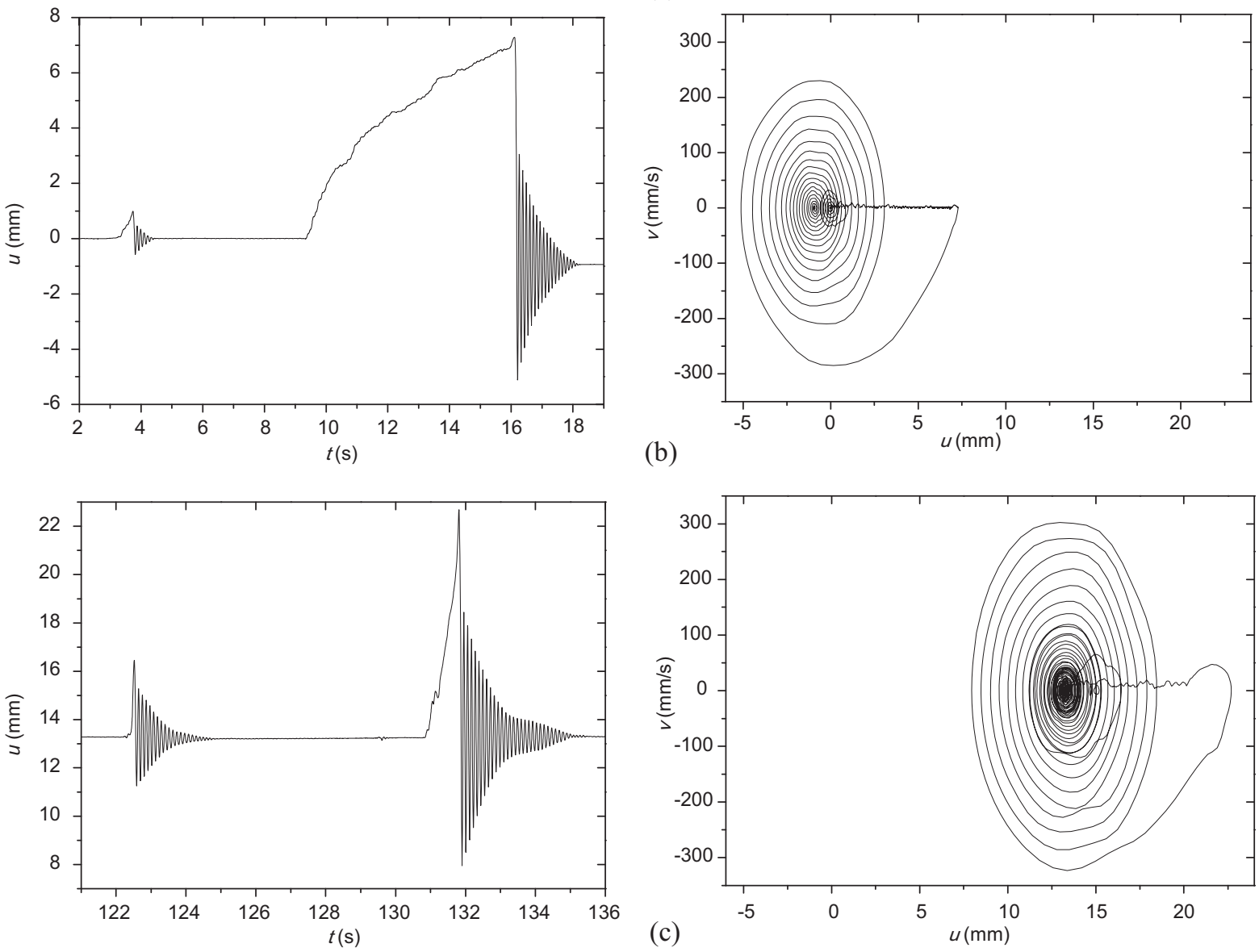

Figure 7. Free vibration analysis: (a) whole test, (b) detail with $0 \mathrm{~A}$, and (c) detail with I.8 A.

versa. On the other hand, hysteresis is due to stressinduced phase transformations. Therefore, the analysis of force-displacement curves allows one to have a better comprehension of the influence of both phenomena on system response. Figure 10(b) presents the forcedisplacement curve during all the process and highlights the behavior at the beginning and at the end of the process that, in principle, are related to steady-state response. The analysis of the force-displacement curves shows that there is a stiffness change during the temperature increase. Although the system has a nonlinear behavior, it is possible to evaluate a slope of the linearized force-displacement curve. At the beginning of the test, when the electric current is $0.8 \mathrm{~A}$, the system presents $k=0.195 \mathrm{~N} / \mathrm{mm}$; at the end of the test, when the electric current is $2.0 \mathrm{~A}$, the stiffness is $k=0.275 \mathrm{~N} /$ $\mathrm{mm}$. Note however that at the beginning of the process, there is a hysteresis loop that dissipates energy. 


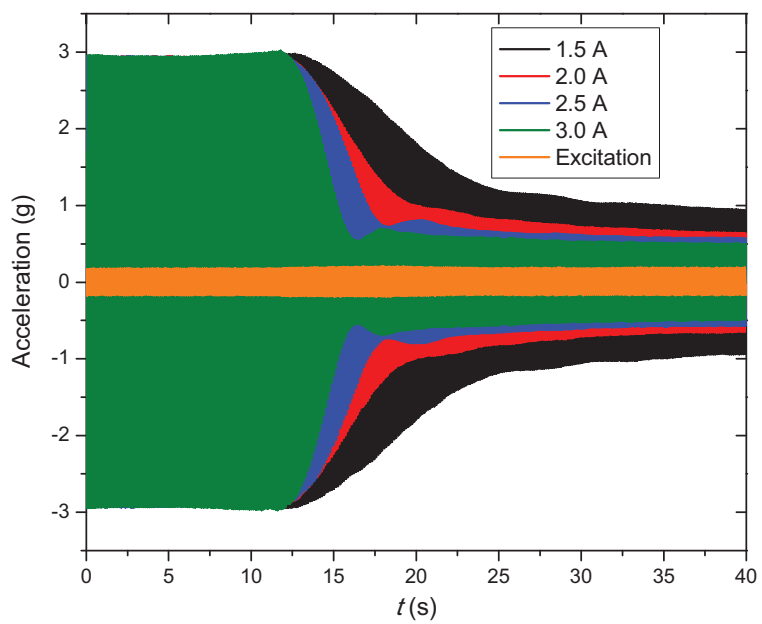

(a)

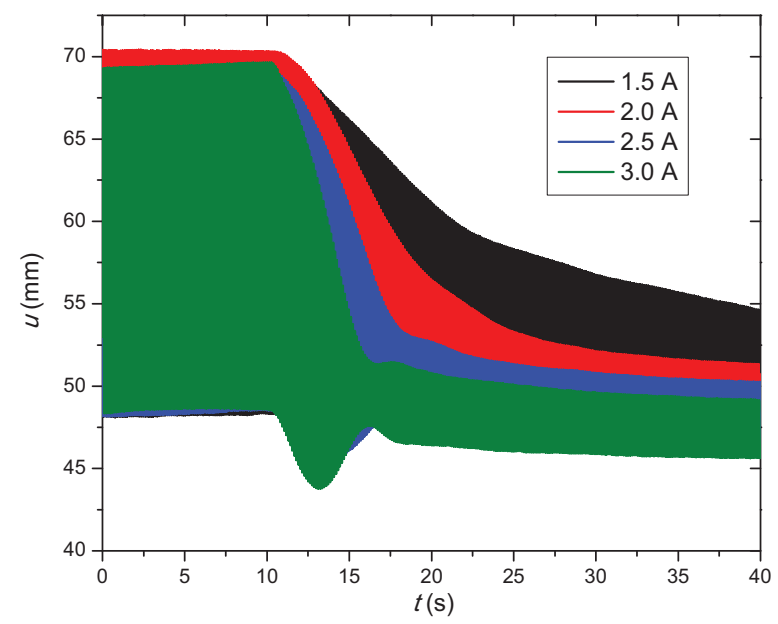

(b)

Figure 8. Vibration reduction promoted by SMA oscillator current variation: (a) acceleration signal and (b) displacement signal. SMA: shape memory alloy. (color in electronic version)

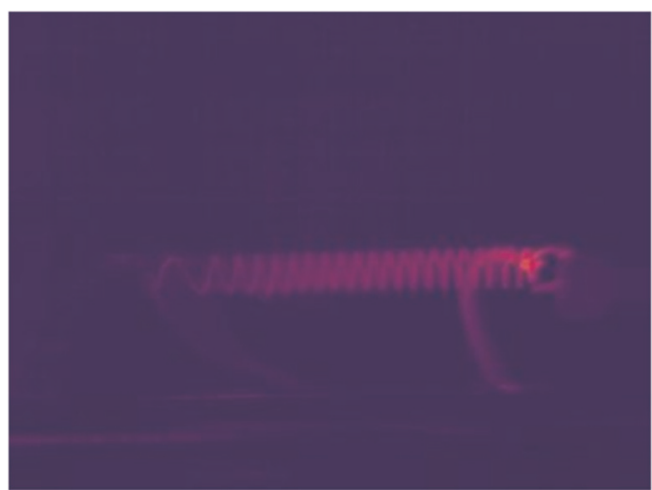

(a)

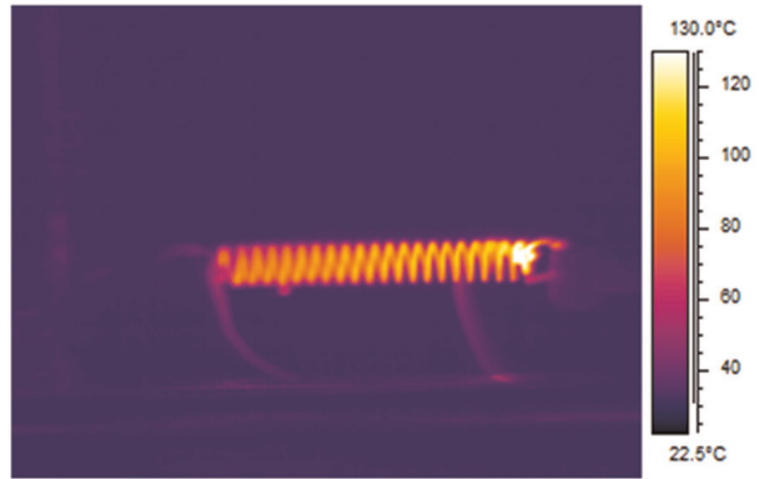

(b)

Figure 9. Thermal infrared image of the SMA spring subjected to an electronic current of (a) $0.8 \mathrm{~A}$ and (b) $3.0 \mathrm{~A}$. SMA: shape memory alloy. (color in electronic version)

Figure 11 presents the phase space of this response. The left panel shows the whole process, while the right panel presents the steady-state response at the beginning and at the end of the process.

Sweep tests are now performed trying to verify the influence of the frequency on the vibration reduction. Basically, a constant amplitude sinusoidal acceleration of $0.25 \mathrm{~g}$ is imposed to the system. The excitation frequency signal changes linearly during the test from 7 to $11 \mathrm{~Hz}$ with $0.02 \mathrm{~Hz} / \mathrm{s}$. Different temperatures are also considered by assuming variation of the electric current: 0.8 and $2.0 \mathrm{~A}$.

A frequency analysis is presented in Figure 12(a) by considering the maximum amplitudes of the acceleration. Note that the peaks can change the position with temperature variation. This behavior defines an important characteristic of this system, that is, the possibility to promote vibration reduction changing the frequency.
Figure 12(b) shows the force-displacement curve. Note that for $0.8 \mathrm{~A}$, the system presents a smaller stiffness but presents a hysteretic behavior. When the temperature increases with the change of the electric current for $2.0 \mathrm{~A}$, the stiffness increases, but the hysteretic behavior is strongly reduced. As a consequence, the system presents higher amplifications under resonant conditions. Therefore, the SMA element may alter the resonant conditions by changing either its position (stiffness change) or its amplification (dissipation).

Based on the previous results, stiffness and hysteresis play a competition to define the vibration conditions. This conclusion can be highlighted by considering preloads that alter the hysteretic behavior of the system. The increase of the preload induces the system to increase its hysteretic behavior. This effect is now investigated by considering different preload conditions in a sine-sweep test performed with 1.2 A. Basically, two 


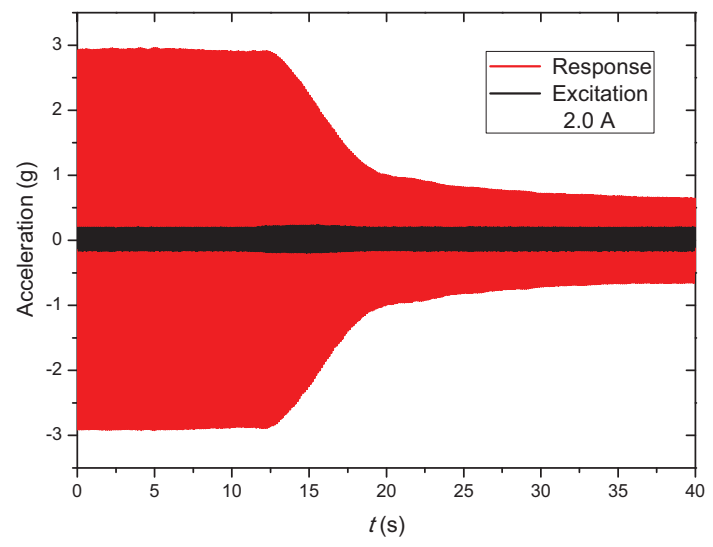

(a)

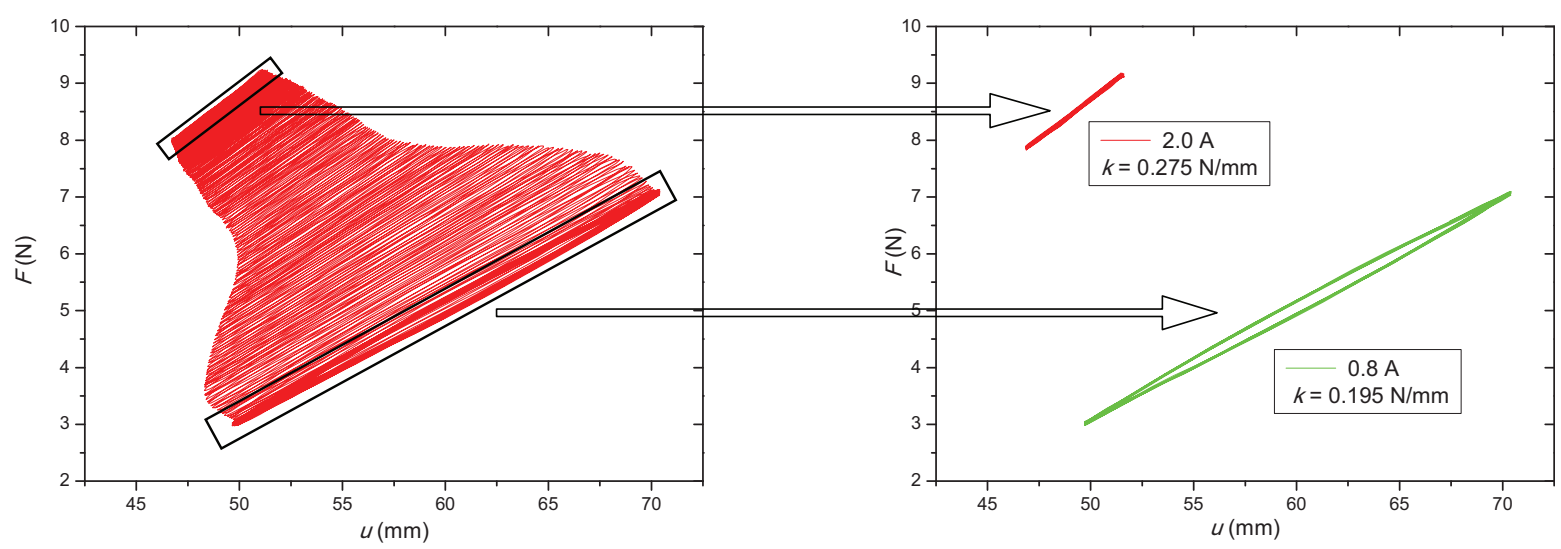

(b)

Figure 10. Vibration reduction promoted by temperature change promoted by an electric current change from 0.8 to $2.0 \mathrm{~A}:$ (a) acceleration and (b) force-displacement curve. (color in electronic version)

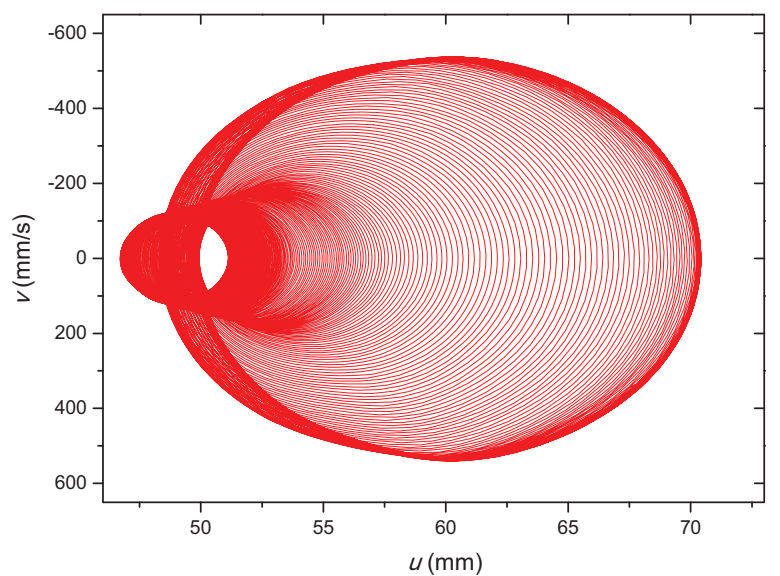

(a)

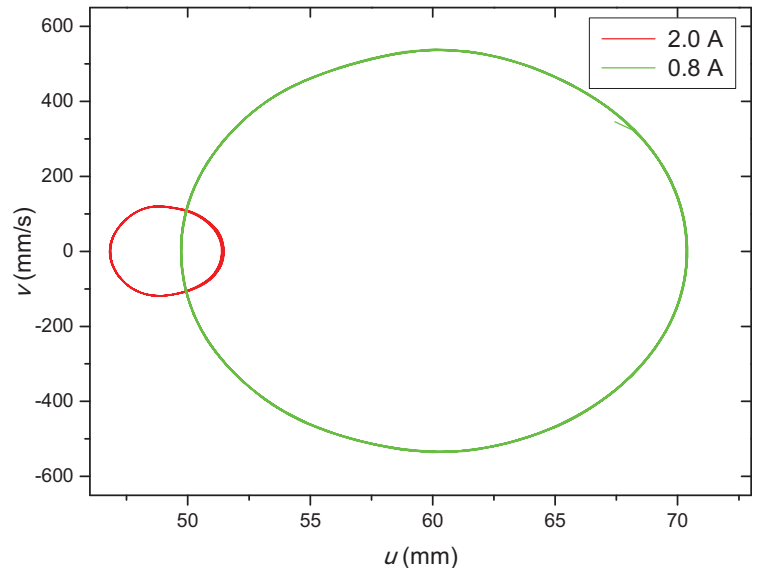

(b)

Figure I I. Vibration reduction promoted by temperature variations imposed by an electric current change from 0.8 to $2.0 \mathrm{~A}:$ (a) phase space showing the whole process and (b) steady-state responses for each electric current. (color in electronic version)

different preload conditions are investigated: 6 and 9 N. Figure 13 shows the sine-sweep response of the SMA oscillator. From the acceleration curves shown in this figure, it is clear that the increase of the preload is associated with the decrease of the amplitudes under resonant conditions. This effect can be explained by considering the force-displacement curve that shows the increase of the hysteretic behavior with the increase 


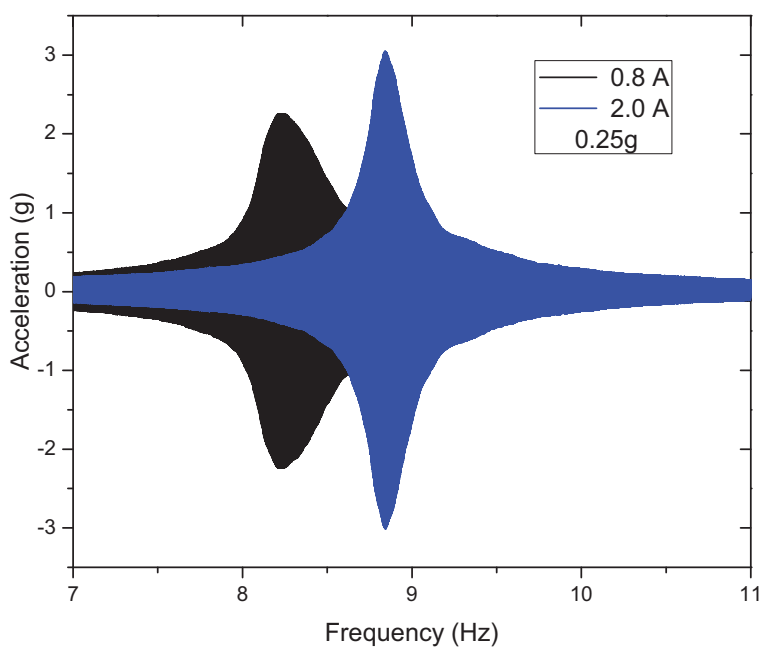

(a)

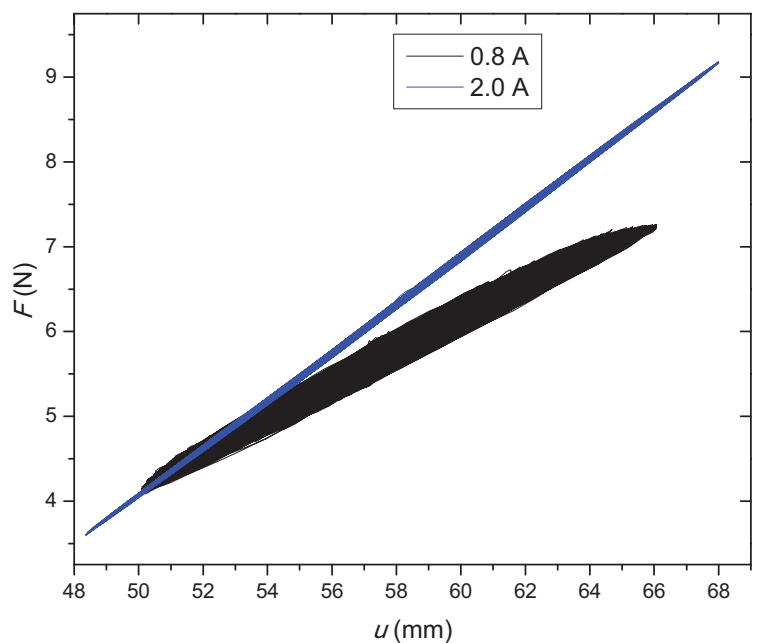

(b)

Figure 12. Sine-sweep tests for different temperatures related to different electric currents: (a) acceleration on frequency domain and (b) force-displacement curves. (color in electronic version)

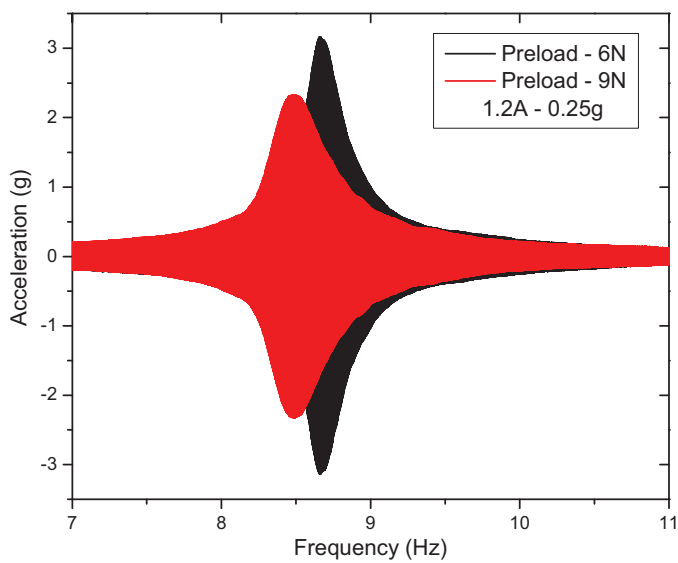

(a)

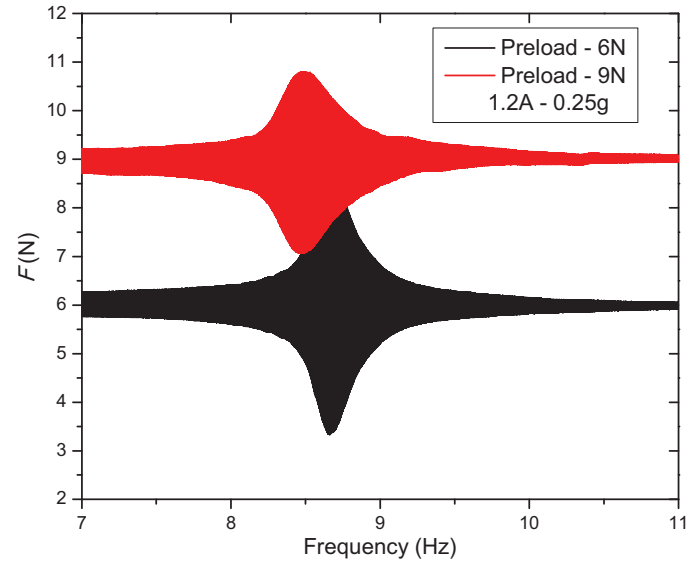

(b)

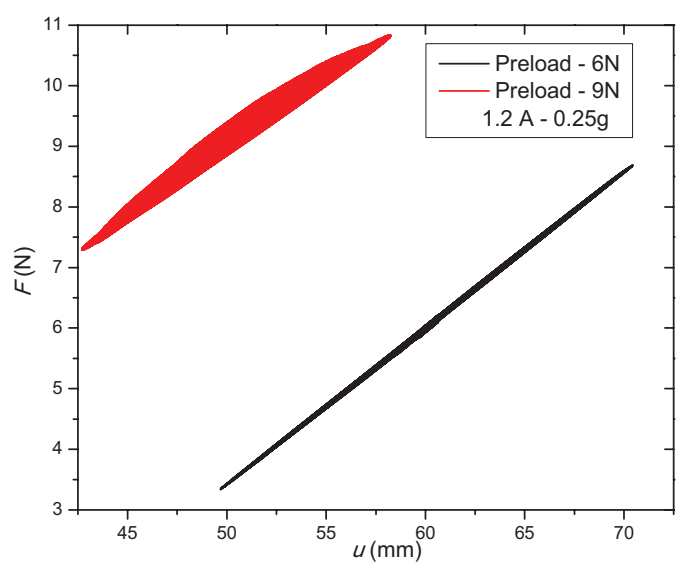

(c)

Figure 13. Preload effect conditions in sine-sweep tests: (a) acceleration on frequency domain, (b) force on frequency domain, and (c) force-displacement curves. (color in electronic version) 


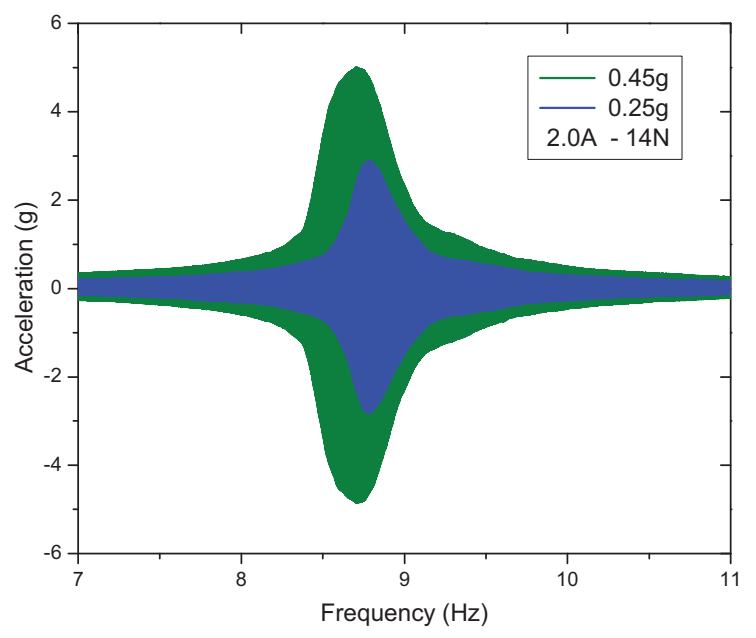

(a)

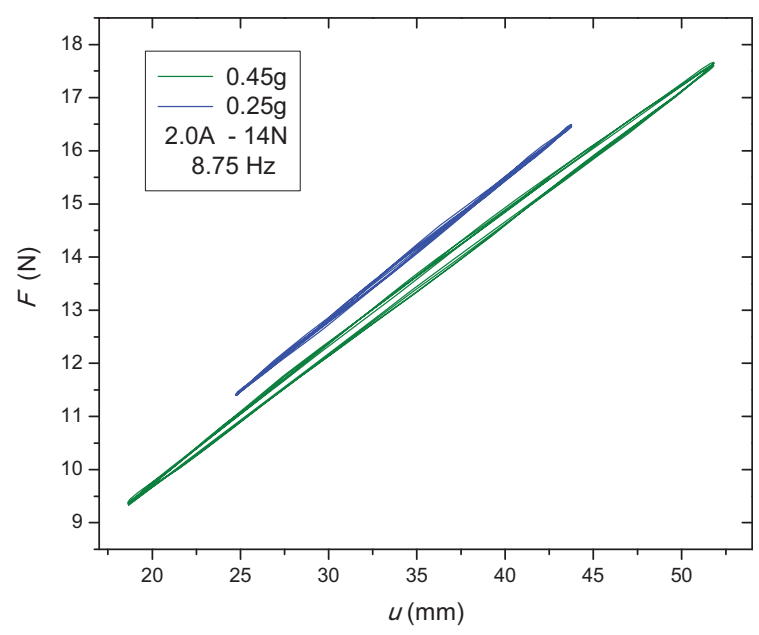

(b)

Figure 14. Effect of different excitation conditions in sine-sweep tests performed with $2.0 \mathrm{~A}$ and I4 $\mathrm{N}$ of preload: (a) acceleration and (b) force-displacement curve. (color in electronic version)

of the preload value. This behavior increases the dissipation and therefore decreases the amplitude gain under resonant conditions.

An important aspect related to hysteretic dissipation is that it can be considered as a smart dissipation in the sense that the more amplitude increases, the more dissipation increases. Figure 14 shows the sine-sweep test performed with $2.0 \mathrm{~A}$ and a preload of $14 \mathrm{~N}$. But now, two different excitations conditions are of concern: $0.25 \mathrm{~g}$ and $0.45 \mathrm{~g}$. By observing the force-displacement curve, it is possible to verify a higher dissipation due to the hysteretic behavior when the excitation is greater $(0.45 \mathrm{~g})$.

\section{DoF system}

At this point, a $2 \mathrm{DoF}$ system is of concern. The basic idea is to represent a vibration absorber with an SMA element. The tuned vibration absorber (TVA) is a well-established passive vibration control device for achieving reduction in the vibration of a primary system subjected to external excitation. The TVA consists of a secondary oscillatory system that once attached to the primary system is capable of absorbing vibration energy from the primary system. By tuning the natural frequency of the TVA to a chosen excitation frequency, one produces an attenuation of the primary system vibration amplitude for this specific forcing frequency. An alternative for systems where the forcing frequency varies or has a kind of uncertainty is the concept of an adaptive TVA (ATVA). This device is an adaptivepassive vibration control similar to a TVA but with adaptive elements that can be used to change the tuned condition. The SMA represents an alternative to be used in ATVA where temperature variations can be used to promote system adaptability (Savi et al., 2011).

The analysis considers two systems: $1 \mathrm{DoF}$ and $2 \mathrm{DoF}$. The $1 \mathrm{DoF}$ system represents some system (primary system) that is connected to a secondary system (forming a $2 \mathrm{DoF}$ system) in order to reduce vibration amplitudes. Therefore, the response of the $1 \mathrm{DoF}$ elastic system is considered as a baseline. The $1 \mathrm{DoF}$ system is composed of a mass (car 1) connected, on one side, to the excitation system by a steel helical spring (spring 2), and, on the other side, to the load cell by a steel helical spring (spring 3). Afterward, a $2 \mathrm{DoF}$ system is considered, connecting a new mass (car 2) to the steel helical spring, on one side, and an SMA spring, on the other side, that is connected to the load cell. The vibration absorber establishes the addition of the secondary system to the $1 \mathrm{DoF}$ oscillator, introducing two resonant conditions, different from the $1 \mathrm{DoF}$ resonant condition. Therefore, there is a tuned frequency indicated for vibration reduction purposes.

Let us start the analysis by considering a test where the primary system is subjected to a harmonic excitation with the amplitude of $0.25 \mathrm{~g}$ and frequency of 6.9 Hz. Initially, the SMA spring is subjected to an electric current of $0.8 \mathrm{~A}$. After $10 \mathrm{~s}$, the SMA spring is subjected to different electric currents reaching the following values: 1.5, 2.0, 2.5, and 3.0 A. Figure 15 presents acceleration of primary (left panel) and secondary (right panel) systems for different electric current values. It is noticeable the amplitude reduction. Figure 16 presents a comparison among the acceleration of the primary and secondary systems, together with the excitation signal. Note that the constant amplitude excitation is reduced in both primary and secondary systems after the electric current increases. Figure 17 presents the displacement 


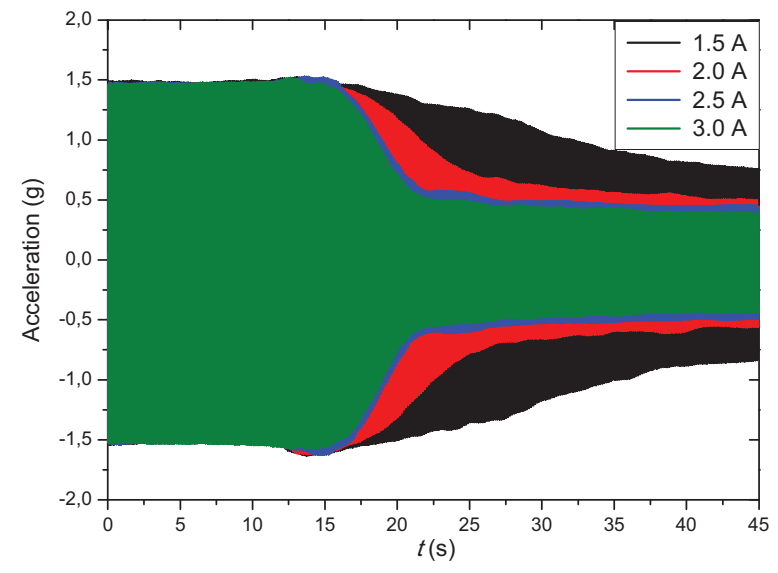

(a)

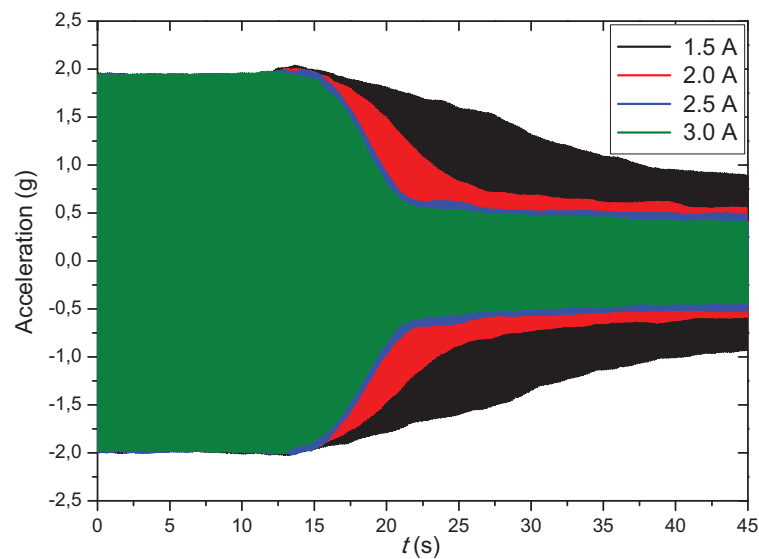

(b)

Figure 15. Vibration reduction of the 2DoF system: (a) primary system and (b) secondary system.

2DoF: two-degree-of-freedom. (color in electronic version)

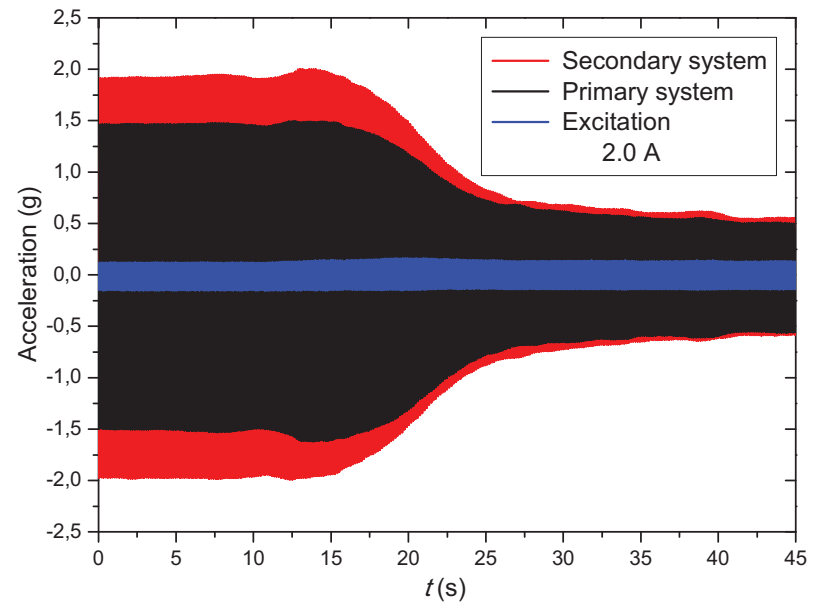

Figure 16. Vibration reduction of the $2 \mathrm{DoF}$ system. 2DoF: two-degree-of-freedom.(color in electronic version)

of the primary system, while Figure 18 shows the phase space of the system, highlighting the whole process and the steady-state responses for each electric current.

Sine-sweep tests are now performed to verify the influence of frequency on the vibration reduction. Basically, the system is harmonically excited with a constant amplitude sinusoidal acceleration of $0.25 \mathrm{~g}$. The excitation frequency signal changes linearly during the test from 6 to $18 \mathrm{~Hz}$ with $0.02 \mathrm{~Hz} / \mathrm{s}$. The results for the $2 \mathrm{DoF}$ system are compared with the results for an elastic $1 \mathrm{DoF}$ system in order to evaluate the performance of the SMA absorber. Different temperatures are considered by assuming variation of the electric currents $(0.8$ and $2.0 \mathrm{~A})$. An essential characteristic of the SMA absorber is the adaptability that allows the alteration of the tuned condition. Figure 19 presents acceleration curves for the $1 \mathrm{DoF}$ and $2 \mathrm{DoF}$ systems with two different electric currents: 0.8 and $2.0 \mathrm{~A}$. It

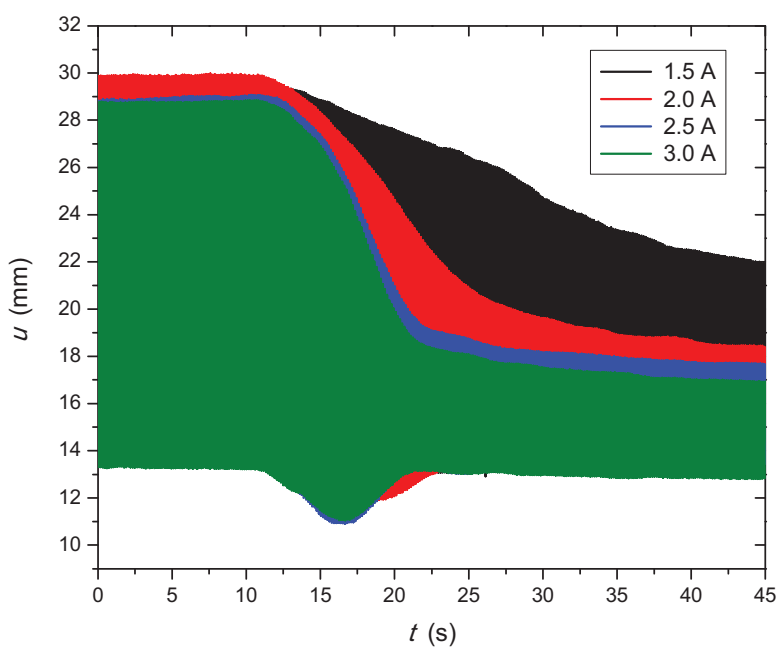

Figure 17. Vibration reduction of the 2DoF systemdisplacement of the primary system. 2DoF: two-degree-of-freedom.(color in electronic version)

should be highlighted that the presented results show that SMA element is useful for vibration reduction purposes and that the temperature change can alter the system response.

A more detailed analysis about the adaptability of the SMA absorber is now in focus. For a frequency of $12.5 \mathrm{~Hz}$, the inclusion of the secondary system promotes a reduction from $5.3 \mathrm{~g}$ to $0.11 \mathrm{~g}$ under resonant conditions of the primary system. However, excitation uncertainties can make the vibration absorber a critical device, especially if the excitation is close to one of the new resonant conditions. This critical situation can be avoided with the adaptive SMA absorber. Figure 20 presents the frequency response of the primary system and shows a specific frequency close to the resonant conditions. By changing the 


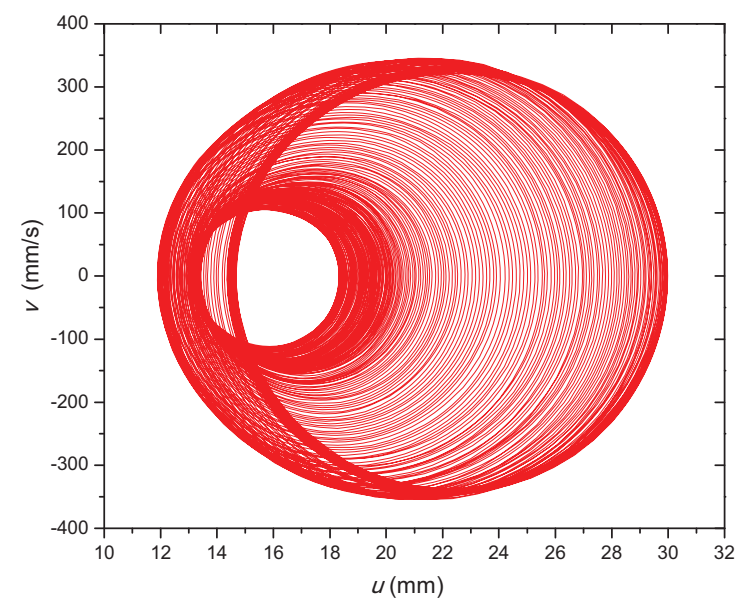

(a)

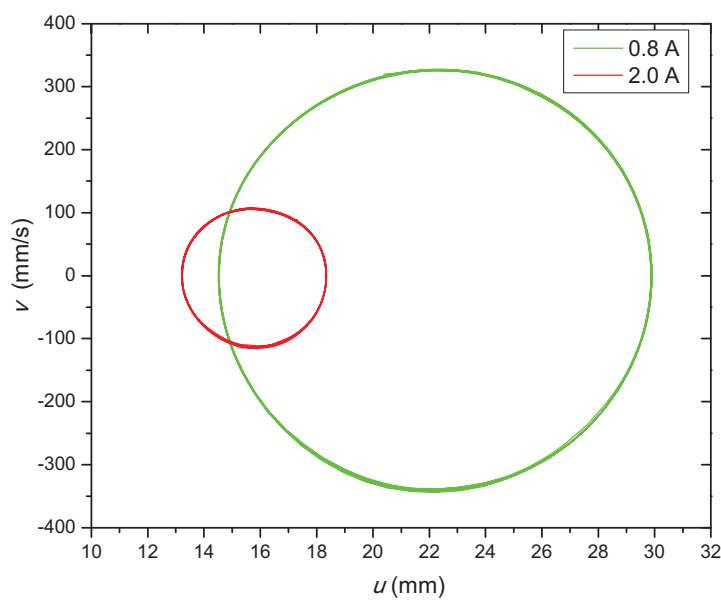

(b)

Figure I 8. Vibration reduction of the primary system promoted by temperature variation promoted by an electric current change from 0.8 to $2.0 \mathrm{~A}$ : (a) phase space showing the whole test and (b) steady-state responses for each electric current.(color in electronic version)

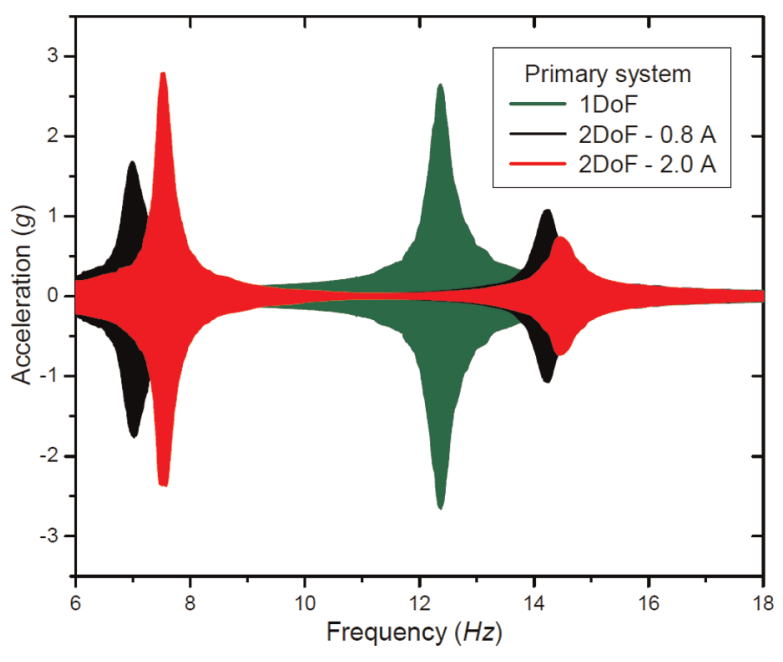

Figure 19. Sine-sweep response of the 2DoF primary system for two different electric currents compared with the elastic IDoF system. (color in electronic version)

2DoF: two-degree-of-freedom; IDoF: one-degree-of-freedom.

temperature (from 0.8 to $2.0 \mathrm{~A}$ ), it is possible to dramatically reduce the system response amplitude (from $1.5 \mathrm{~g}$ to $0.35 \mathrm{~g})$.

\section{Conclusion}

This article deals with an experimental investigation of nonlinear dynamics of SMA systems. An experimental rig composed of low-friction cars free to move in a rail is designed and built in order to evaluate the complex behavior of SMA dynamical systems. Two different systems are treated: $1 \mathrm{DoF}$ and $2 \mathrm{DoF}$. Concerning the $1 \mathrm{DoF}$ system, initially free vibration

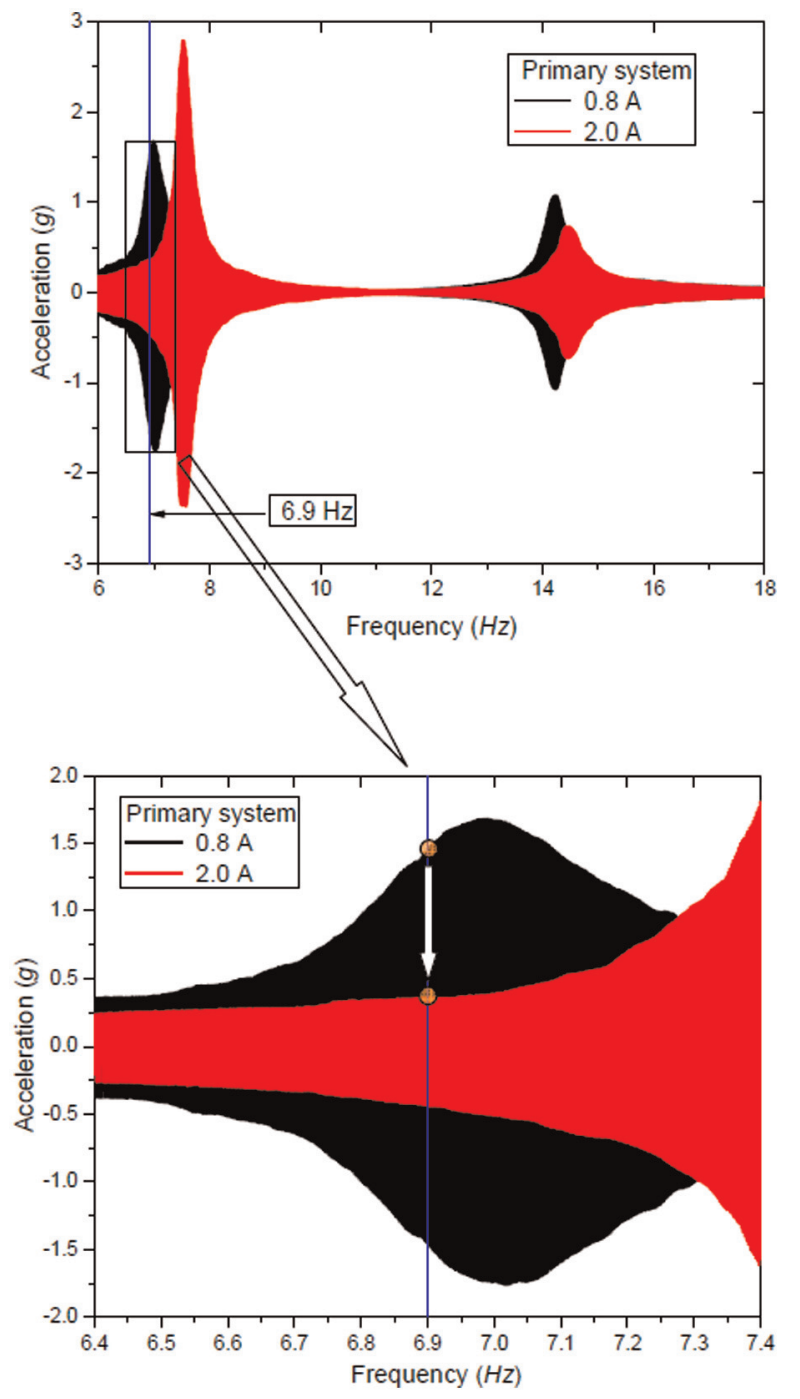

Figure 20. Primary system response amplitude reduction with an adaptive SMA vibration absorber. (color in electronic version) 
analysis is treated, showing the temperature dependence of the response. Basically, it is possible to change oscillation positions by altering the temperature. The forced vibration analysis shows the vibration reduction due to temperature variations. Two different aspects influence the system response: stiffness change and hysteretic behavior. Stiffness change alters resonant frequency. On the other hand, changes related to the hysteretic behavior contribute to reduce vibration amplitudes under resonant conditions due to dissipation changes. Therefore, both things establish a competition that defines the system response. This argument is investigated by considering different preload conditions imposed to the SMA element, and the results confirm that the increase of the preload induces larger hysteretic behavior. The $2 \mathrm{DoF}$ system analysis represents an adaptive vibration absorber with SMA element. Therefore, there is a primary system connected to a secondary system with SMA spring. Once again, vibration reduction can be achieved, and it is important to highlight the adaptive characteristic of the SMA system that has the capacity to change the tuned frequency with the temperature variation.

\section{Funding}

This research received no specific grant from any funding agency in the public, commercial, or not-for-profit sectors.

\section{Acknowledgements}

The authors would like to thank the Brazilian Research Agencies CNPq, CAPES, and FAPERJ and through the INCT-EIE (National Institute of Science and TechnologySmart Structures in Engineering), the CNPq and FAPEMIG for their support. The Air Force Office of Scientific Research (AFOSR) is also acknowledged.

\section{References}

Aguiar RAA, Savi MA and Pacheco PMCL (2010) Experimental and numerical investigations of shape memory alloy helical springs (article 025008). Smart Materials and Structures 19(2): 1-9.

Bernardini D and Rega G (2005) Thermomechanical modelling, nonlinear dynamics and chaos in shape memory oscillators. Mathematical and Computer Modelling of Dynamical Systems 11(3): 291-314.

Bernardini D and Rega G (2011a) Chaos robustness and strength in thermomechanical shape memory oscillators. Part I: a predictive theoretical framework for the pseudoelastic behavior. Part II: numerical and theoretical evaluation. International Journal of Bifurcation and Chaos 21(10): 2769-2782.

Bernardini D and Rega G (2011b) Chaos robustness and strength in thermomechanical shape memory oscillators. Part II: numerical and theoretical evaluation. International Journal of Bifurcation and Chaos 21(10): 2783-2800.
Birman V (2008) Shape memory elastic foundation and supports for passive vibration control of composite plates. International Journal of Solids and Structures 45: 320-335.

Denoyer KK, Erwin RS and Ninneman RR (2000) Advanced smart structures flight experiments for precision spacecraft. Acta Astronautica 47: 389-397.

Elahinia MH, Koo JH and Tan H (2005) Improving robustness of tuned vibration absorbers using shape memory alloys. Shock and Vibration 12(5): 349-361.

Lagoudas DC (2008) Shape Memory Alloys: Modeling and Engineering Applications. New York, NY, USA: Springer.

Machado LG and Savi MA (2002) Odontological applications of shape memory alloys. Revista Brasileira de Odontologia 59(5): 302-306.

Machado LG and Savi MA (2003) Medical applications of shape memory alloys. Brazilian Journal of Medical and Biological Research 36(6): 683-691.

Machado LG, Lagoudas DC and Savi MA (2009) Lyapunov exponents estimation for hysteretic systems. International Journal of Solids and Structures 46: 1269-1286.

Machado LG, Savi MA and Pacheco PMCL (2003) Nonlinear Dynamics and Chaos in Coupled Shape Memory Oscillators. International Journal of Solids and Structures 40(19): 5139-5156.

Nae FA, Ikeda T and Matsuzaki Y (2004) The active tuning of a shape memory alloy pseudoelastic property. Smart Materials and Structures 13: 503-511.

Paiva A and Savi MA (2006) An overview of constitutive models for shape memory alloys (article ID56876). Mathematical Problems in Engineering 2006: 1-30.

Rustighi E, Brennan MJ and Mace BR (2003) Design of an adaptive vibration absorbers using shape memory alloy. University of Southampton, Institute of Sound and Vibration, SVR - Technical Memorandum No. 920.

Rustighi E, Brennan MJ and Mace BR (2005a) A shape memory alloy adaptive tuned vibration absorber: design and implementation. Smart Materials and Structures 14: 19-28.

Rustighi E, Brennan MJ and Mace BR (2005b) Real-time control of a shape memory alloy adaptive tuned vibration absorber. Smart Materials and Structures 14: 1184-1195.

Santos BC and Savi MA (2009) Nonlinear dynamics of a nonsmooth shape memory alloy oscillator. Chaos, Solitons and Fractals 40(1): 197-209.

Savi MA and Pacheco PMCL (2002) Chaos and hyperchaos in shape memory systems. International Journal of Bifurcation and Chaos 12(3): 645-657.

Savi MA, De Paula AS and Lagoudas DC (2011) Numerical investigation of an adaptive vibration absorber using shape memory alloys. Journal of Intelligent Material Systems and Structures 22(1): 67-80.

Savi MA, Pacheco PMCL and Braga AMB (2002) Chaos in a shape memory two-bar truss. International Journal of Non-Linear Mechanics 37(8): 1387-1395.

Savi MA, Sa MAN, Paiva A, et al. (2008) Tensile-compressive asymmetry influence on the shape memory alloy system dynamics. Chaos, Solitons and Fractals 36: 828-842.

Sitnikova E, Pavlovskaia E, Wiercigroch M, et al. (2010) Vibration reduction of the impact system by an SMA restraint: numerical studies. International Journal of NonLinear Mechanics 45(9): 837-849. 
Tiseo B, Concilio A, Amerudi S, et al. (2010) A shape memory alloy based tuneable dynamic vibration absorber for vibration tonal control. Journal of Theoretical and Applied Mechanics 48: 135-153.

Van Humbeeck J (1999) Non-medical applications of shape memory alloys. Materials Science and Engineering A 273275: 134-148.

Webb G, Wilson L, Lagoudas DC, et al. (2000) Adaptive control of shape memory alloy actuators for underwater biomimetic applications. AIAA Journal 38(2): 325-334.
Williams KA, Chiu GCC and Bernhard RJ (2001) Stability analysis of a shape memory alloy adaptive tuned vibration absorber under pi control with anti-windup. In: Proceedings of 2001 ASME international mechanical engineering congress and exposition, 11-16 November, New York.

Williams KA, Chiu GCC and Bernhard RJ (2002) Adaptivepassive absorbers using shape-memory alloys. Journal of Sound and Vibration 249: 835-848.

Williams KA, Chiu GCC and Bernhard RJ (2005) Nonlinear control of a shape memory alloy adaptive tuned vibration absorber. Journal of Sound and Vibration 288: 1131-1155. 